\title{
Combination Therapy of Etanercept and Fumarates versus Etanercept Monotherapy in Psoriasis: A Randomized Exploratory Study
}

\author{
Ji Sun van Bezooijen ${ }^{a}$ b Deepak M.W. Balak ${ }^{a}$ Martijn B.A. van Doorn ${ }^{a}$ \\ Caspar W.N. Looman ${ }^{\text {e }}$ Marco W.J. Schreurs ${ }^{d}$ Birgit C.P. Koch ${ }^{b}$ \\ Teun van Gelder ${ }^{b, c}$ Errol P. Prens ${ }^{a}$ \\ Departments of a Dermatology, ${ }^{b}$ Hospital Pharmacy, ${ }^{c}$ Internal Medicine, ${ }^{d}$ Immunology, and e Public Health, \\ Erasmus MC, Rotterdam, The Netherlands
}

\section{Key Words}

Etanercept · Fumarates · Biologics · Combination therapy · Psoriasis

\begin{abstract}
Background: Biologics are a safe and efficacious therapy for psoriasis. The drug survival of biologics may be disappointing, primarily due to loss of efficacy. Therefore, safe combination treatments are sought to improve their clinical response. Objective: To assess the efficacy, safety and tolerability of the combination therapy of etanercept with fumarates versus etanercept monotherapy. Methods: Thirty-three patients with psoriasis were randomized 1:1 to receive etanercept combined with fumarates or etanercept monotherapy. The primary outcome measure was the difference in PASI-75 response after 24 weeks; additionally, a longitudinal analysis was performed. An important secondary outcome measure was the proportion of patients with a Physician Global Assessment (PGA) of clear or almost clear. Adverse events were collected throughout the study. Results: In the combination therapy group, 78\% (14 out of 18 patients) reached PASI- 75 at week 24 versus 57\% (8 out of 14 patients) in the monotherapy group $(p=0.27)$. The longitudinal analysis showed a PASI reduction of $5.97 \%$ per week for
\end{abstract}

the combination therapy group and of $4.76 \%$ for the monotherapy group $(p=0.11)$. In the combination therapy group, 94\% (17 out of 18 patients) of patients had a PGA of clear/ almost clear versus $64 \%$ ( 9 out of 14 patients) in the monotherapy group $(p=0.064)$. The incidence of mild gastrointestinal complaints was higher in the combination group than in the monotherapy group. Conclusion: Using the PGA, combination therapy showed a trend towards faster improvement in the first 24 weeks. The difference in the PASI score between the two groups was not statistically significant. Addition of fumarates to etanercept for 48 weeks appeared safe with an acceptable tolerability.

(c) 2016 The Author(s)

Published byS. Karger AG, Basel

\section{Background}

Psoriasis is a chronic, immune-mediated inflammatory skin disease affecting approximately $1-3 \%$ of the Caucasian population [1]. In most patients, psoriasis has a relapsing course that considerably impairs their quality of life $[2,3]$. Biologics are effective drugs that are capable of inducing a rapid and meaningful clinical improvement. However, the drug survival of anti-tumour necrosis factor (TNF)- $\alpha$ biologics in clinical practice appears 


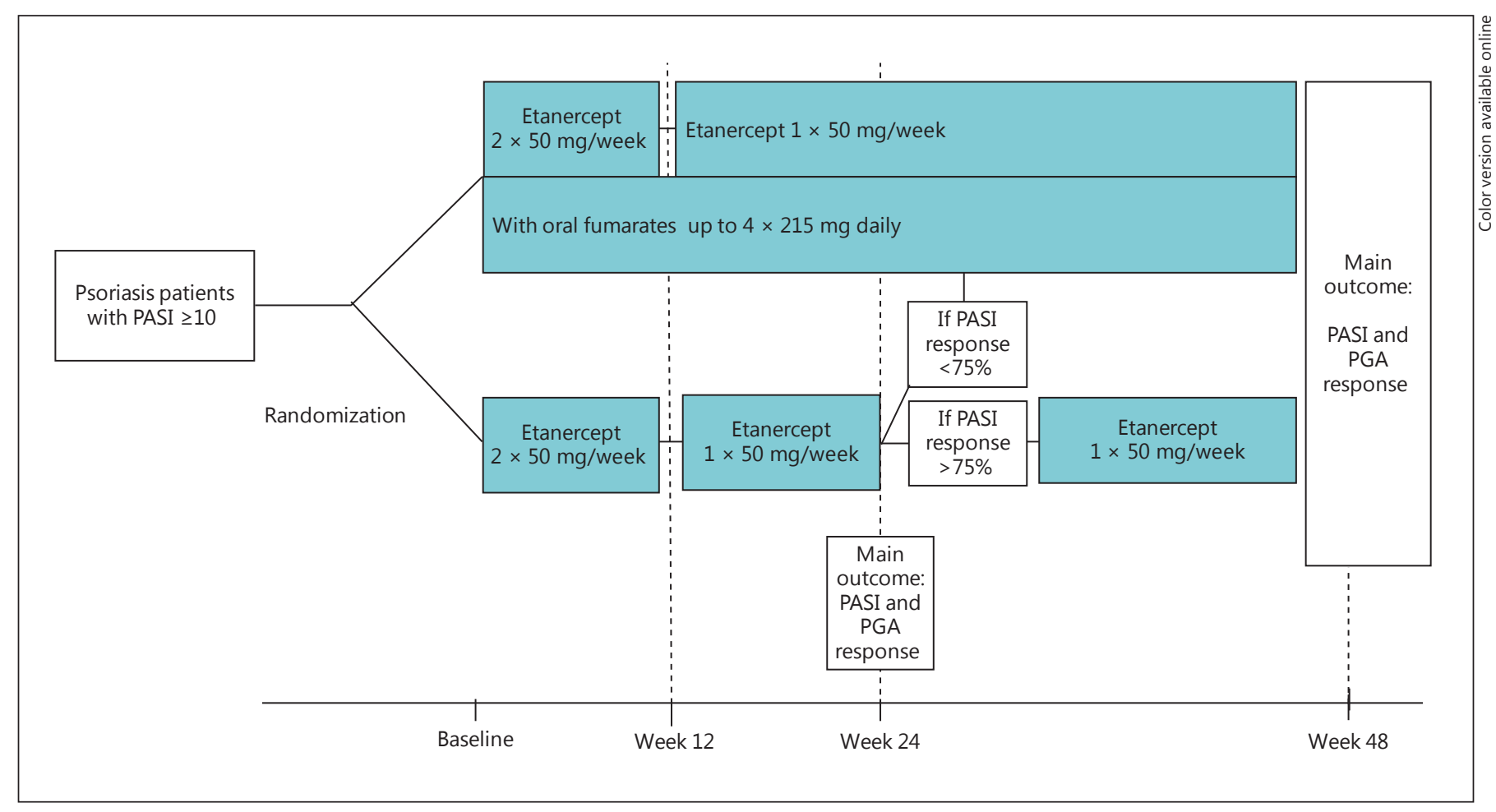

Fig. 1. A schematic flow chart representing the study methods for the exploratory study comparing etanercept monotherapy versus combination therapy with fumarates.

disappointing, mainly due to a gradual loss of efficacy over time $[4,5]$. In a prospective Danish registry, etanercept had a limited drug survival with a median survival of 30 months after a 10-year follow-up. Loss of efficacy was the primary reason for $67 \%$ of discontinuations for all biologics [6-8].

Etanercept binds and neutralizes TNF- $\alpha$ via a recombinant soluble p75 TNF- $\alpha$ receptor fused to an IgG1 constant chain and combines a satisfactory efficacy with a favourable safety profile [9]. Despite the increasing use of interleukin-12/23 and interleukin-17 inhibitors in the treatment of psoriasis, etanercept is still widely used in clinical practice. Several studies have shown that after 12 weeks of treatment with the recommended induction dose of $2 \times 50 \mathrm{mg} /$ week, approximately $50 \%$ of the patients achieve a $75 \%$ or greater improvement in their psoriasis area and severity index (PASI-75 response) [9-12]. After the induction phase of $2 \times 50 \mathrm{mg}$ weekly, current guidelines and the label recommend reducing the dose of etanercept to $1 \times 50 \mathrm{mg}$ weekly from week 12 onwards [13]. However, at this once weekly dosage, the clinical response deteriorates in many patients. Van den Reek et al. [7] showed that $33.7 \%$ of patients discontinued etaner- cept because of deterioration of their psoriasis at this dosage. An option to counteract this loss of efficacy is to combine etanercept with other systemic agents [14-17]. The ester derivatives of fumaric acid are mainly used in the Netherlands and Germany as a first-line systemic drug for moderate to severe psoriasis. Fumaric acid esters, or fumarates, have been in use for the treatment of psoriasis for over 4 decades and are considered safe and effective as long as the treatment guidelines are followed [18-22]. The fumaric acid ester derivative dimethylfumarate is metabolized in the body to monomethylfumarate, which is regarded as the most bio-active metabolite. In daily clinical practice, we noted in some patients that the addition of oral fumarates to etanercept $50 \mathrm{mg}$ once weekly improved the clinical response and drug survival [pers. unpubl. observation]. At present, evidence supporting the safety of the combination therapy of etanercept and fumarates in psoriasis is virtually lacking. Therefore, it is not recognized as a feasible treatment option among dermatologists. In this exploratory study the key objectives were to evaluate the efficacy, safety and tolerability of the combination therapy of etanercept with fumarates in psoriasis. 


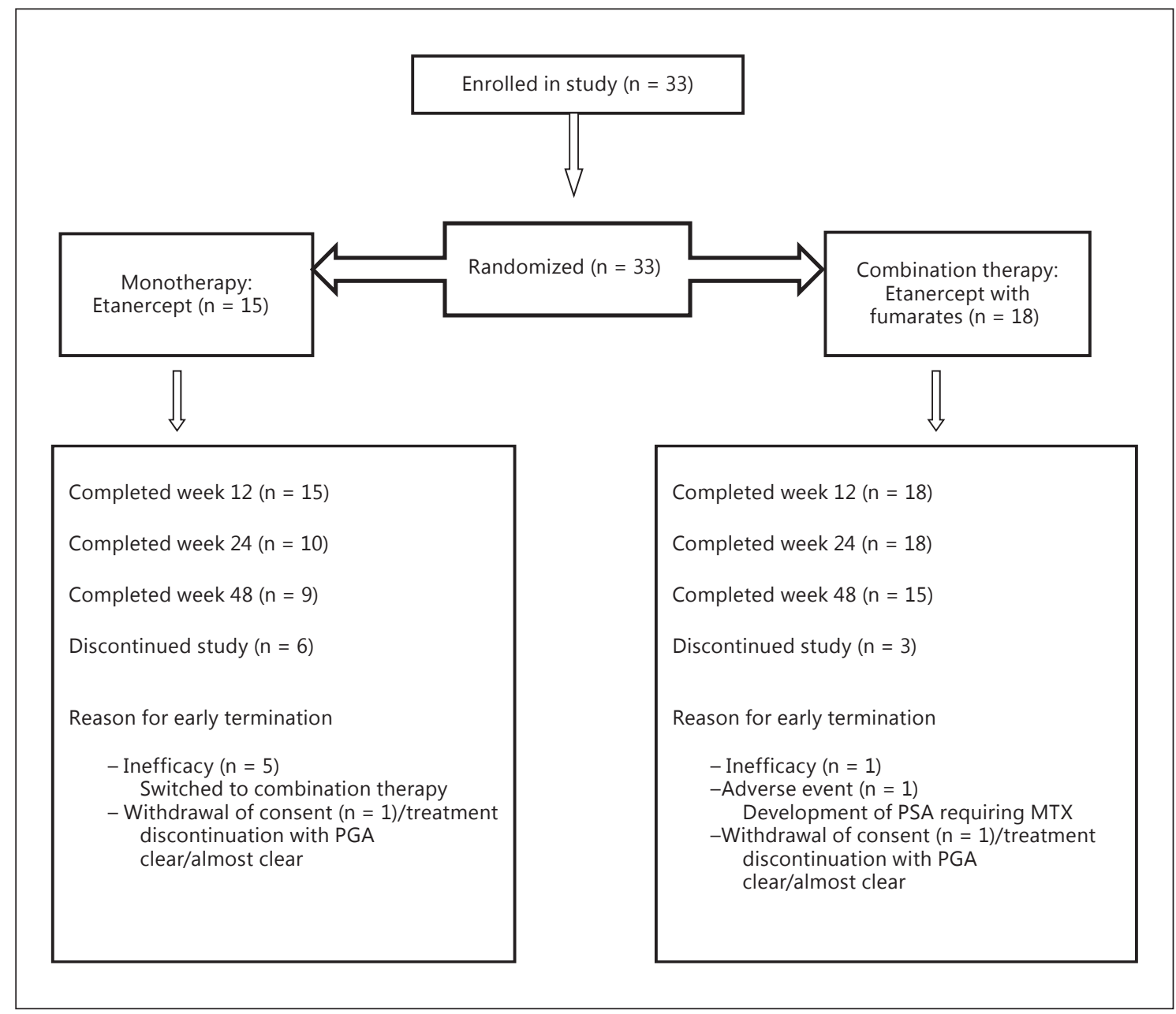

Fig. 2. Schematic representation of included, randomized and evaluable patients for the combination therapy and for the monotherapy group.

\section{Methods}

For further details, see the supplementary materials (for all online suppl. material, see www.karger.com/doi/10.1159/000448135) (fig. 1, 2; online suppl. fig. 1,2).

\section{Results}

\section{Patients}

In total 33 patients were enrolled: 15 patients were randomized to etanercept monotherapy and 18 patients to combination therapy with etanercept and fumarates.

Patient demographics and baseline disease characteristics are shown in table 1 . At baseline only the body mass index and previous use of biologics differed significantly between the combination and monotherapy groups $(\mathrm{p}<$ 0.05 ). The flow chart in figure 2 shows the number of patients who were enrolled and dropped out from the study together with the reasons for discontinuation. Twentytwo out of 33 patients (67\%) finished the entire study. In the monotherapy group, 9 of 15 patients $(60 \%)$ completed the study and in the combination therapy group 13 of 18 patients $(72 \% ; \mathrm{p}=0.71)$.

\section{Clinical Efficacy}

The PASI-75 response is presented in table 2 for both groups. The difference between the two groups was not statistically significant at all time points. In both groups, all patients showed a clear improvement in their PASI score from baseline. The longitudinal analysis demon- 
Table 1. Baseline patient characteristics according to treatment arm

\begin{tabular}{|c|c|c|}
\hline Patient characteristics & $\begin{array}{l}\text { Monotherapy } \\
\text { etanercept } \\
(\mathrm{n}=15)\end{array}$ & $\begin{array}{l}\text { Combination } \\
\text { therapy } \\
\text { etanercept with } \\
\text { fumarates } \\
(\mathrm{n}=18)\end{array}$ \\
\hline \multicolumn{3}{|l|}{ Gender, $\mathrm{n}$} \\
\hline Males & $8(53)$ & $14(78)$ \\
\hline Females & $7(47)$ & $4(22)$ \\
\hline Mean age $\pm S D$, years & $45 \pm 16$ & $43 \pm 17$ \\
\hline Mean height $\pm \mathrm{SD}, \mathrm{m}$ & $1.72 \pm 0.13$ & $1.77 \pm 0.11$ \\
\hline Mean $\mathrm{BMI} \pm \mathrm{SD}$ & $30 \pm 6^{*}$ & $26 \pm 6^{*}$ \\
\hline \multicolumn{3}{|l|}{ PGA score, $\mathrm{n}$} \\
\hline Moderate & $6(40)$ & $13(72)$ \\
\hline Severe & $9(60)$ & $5(28)$ \\
\hline Median PASI score & $14[11,21]$ & $12[10,16]$ \\
\hline Median DLQI score & $9[5,20]$ & $8[3,13]$ \\
\hline \multicolumn{3}{|l|}{ Mean duration of psoriasis } \\
\hline$\pm \mathrm{SD}$, years & $19(10)$ & $22(10)$ \\
\hline History of psoriatic arthritis, $n$ & $1(7)$ & $5(28)$ \\
\hline \multicolumn{3}{|l|}{ Prior therapy, $\mathrm{n}$} \\
\hline UVB/PUVA & $15(93)$ & $17(94)$ \\
\hline Fumarates & $13(87)$ & $11(61)$ \\
\hline Methotrexate & $13(87)$ & $13(72)$ \\
\hline Cyclosporin & $4(27)$ & $6(33)$ \\
\hline Acitretin & $6(40)$ & $10(56)$ \\
\hline Biologic & $3(20)^{*}$ & $10(56)^{*}$ \\
\hline
\end{tabular}

* $\mathrm{p}<0.05$ : statistically significantly different between monotherapy and combination group. Figures in parentheses are percentages, those in square brackets first and third quartiles. strated a reduction of the PASI score for the combination therapy and monotherapy group from baseline up to week 48. All observations were made in a 4-week period separated into two groups; the medians per group per time are shown in figure 3. The reduction in the PASI score per week for the combination therapy was $5.97 \%$ (95\% confidence interval, CI: 5.08-6.85) and in the monotherapy group $4.76 \%$ (95\% CI: 3.57-5.93; p = 0.11). In the online supplementary data, figures 1 and 2 show the changes in the PASI score per patient. Five patients who did not respond sufficiently to monotherapy were switched to combination therapy at week 24 according to the protocol. Only 1 out of 5 switchers achieved a PASI-75 improvement after 24 weeks of combination treatment.

The proportion of patients with a Physician Global Assessment (PGA) score of clear or almost clear is presented in table 2.

The drug survival in the monotherapy group was $60 \%$ after 48 weeks. Nine out of 15 patients (60\%) remained under etanercept therapy after 48 weeks. The drug survival in the combination group was $72 \%$. Thirteen out of 18 patients (72\%) remained under etanercept with fumarate treatment after 48 weeks. The drug survival was not significantly different for the combination therapy group compared with the monotherapy group: $72 \%$ (95\% CI: 51-93) versus 60\% (95\% CI: 35-85), with $\mathrm{p}=0.71$.

The time to the onset of action was 9 weeks for both groups.

Table 2. Statistical analysis of PASI-75 response and PGA score (\%)

\begin{tabular}{|c|c|c|c|c|c|}
\hline & $\begin{array}{l}\text { Monotherapy } \\
\text { etanercept } \\
(\mathrm{n}=15)\end{array}$ & $\begin{array}{l}\text { Absolute } \\
\text { numbers }\end{array}$ & $\begin{array}{l}\text { Combination } \\
\text { therapy } \\
\text { etanercept with } \\
\text { fumarates } \\
(\mathrm{n}=18)\end{array}$ & $\begin{array}{l}\text { Absolute } \\
\text { numbers }\end{array}$ & $\mathrm{p}$ value \\
\hline PASI-75 at week 12 & $64(39-89)$ & 9 out of 14 & $67(42-91)$ & 12 out of 18 & $1.00^{\mathrm{a}}$ \\
\hline PASI-75 at week 24 & $57(31-83)$ & 8 out of 14 & $78(59-97)$ & 14 out of 18 & $0.27^{\mathrm{b}}$ \\
\hline PGA (clear/almost clear) at week 24 & $64(39-89)$ & 9 out of 14 & $94(84-105)$ & 17 out of 18 & $0.064^{\mathrm{b}}$ \\
\hline PGA (clear/almost clear) at week 48 & $64(39-89)$ & 9 out of 14 & $87(70-104)$ & 13 out of 15 & $0.22^{\mathrm{b}}$ \\
\hline
\end{tabular}

Results are expressed as means with $95 \%$ confidence intervals in parentheses. Missing data: 1 patient in the monotherapy group had missing visits at weeks 12 and 24; 1 patient in the monotherapy group and 3 patients in the combination therapy group were lost to follow-up at week 48. As a consequence, these patients were not included in the statistical analysis of the PASI-75 and PGA score. ${ }^{\mathrm{a}} \chi^{2}$ test. ${ }^{\mathrm{b}}$ Fisher's exact test. 
Quality of Life (Dermatology Quality of Life Index) and Treatment Satisfaction (Visual Analogue Scale)

The results of the median change in the Dermatology Quality of Life Index (DLQI) score are shown in table 3. In both groups, DLQI scores decreased significantly over time. The difference between the two groups at 24 and 48 weeks was not statistically significant. The results of the visual analogue scale scores on treatment satisfaction are shown in table 4. Similar to the DLQI scores, the differences between the two groups did not reach statistical significance at either 24 or 48 weeks. The 5 switchers were excluded from the analysis.

\section{Adverse Events}

The most frequently reported adverse event in the monotherapy group was flu-like symptoms, present in 9 versus 14 in the combination therapy group. Gastrointestinal complaints (38), consisting of diarrhoea and abdominal cramps, were most frequently observed in the combination therapy group compared to the monotherapy group (1). One patient developed iron deficiency anaemia, which was caused by a carcinoma of the rectum.
This was diagnosed after the patient had finished the study and was considered not to be related to the study medication. None of the (severe) adverse events led to discontinuation of the study. No leucopenia and/or lymphopenia was observed in either treatment group. All adverse events are listed in table 5.

\section{Discussion}

In this exploratory randomized study we prospectively compared the clinical efficacy, safety, and tolerability of etanercept with oral fumarates in combination therapy with etanercept monotherapy per label up to 48 weeks of treatment. The assumption was that addition of fumarates would be a safe and low-cost option to increase the clinical efficacy and drug survival of etanercept. The primary outcome of this study was that the combination treatment led to a numerically higher efficacy compared to etanercept monotherapy (78 vs. $57 \%$ PASI-75) at week 24. However, the numerical differences in efficacy were not statistically significant. Also the longitudinal analysis
Fig. 3. The results of a longitudinal analysis using a linear mixed model demonstrating the reduction of the PASI score for the combination therapy and monotherapy groups from baseline up to week 48 . All observations were made in a 4 -week period separated into two groups; the medians per group per time are shown in the graph. We used log-transformed PASI in the regression model to achieve changes to be relative. This is consistent with presenting medians at the original scale.

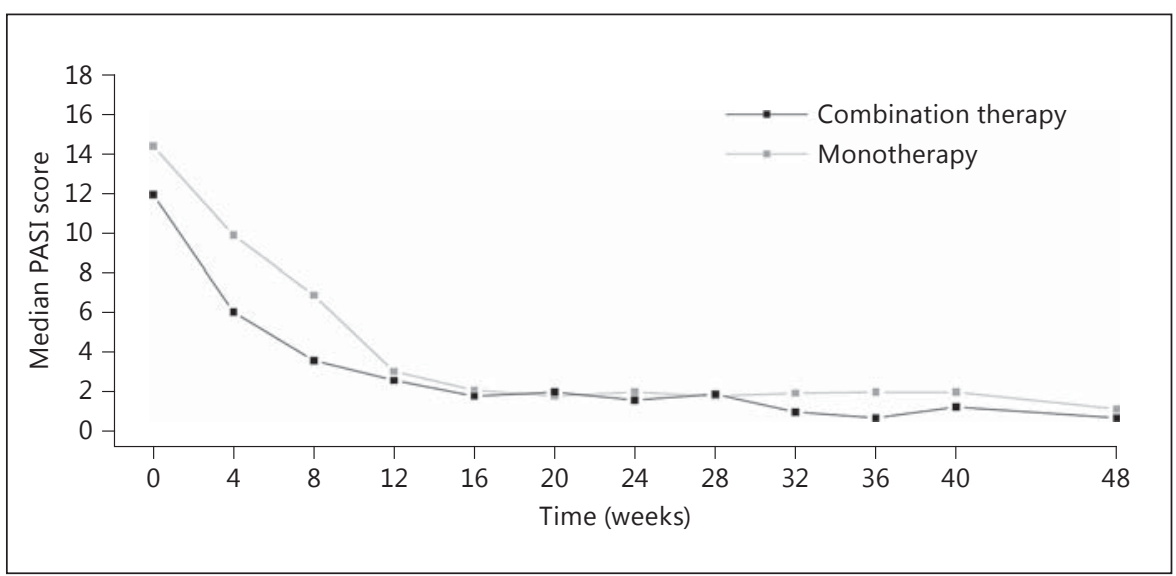

Table 3. Dermatology Life Quality Index (DLQI) during treatment

\begin{tabular}{llll}
\hline & $\begin{array}{l}\text { Change in DLQI } \\
\text { in monotherapy } \\
\text { etanercept }\end{array}$ & $\begin{array}{l}\text { Change in DLQI in } \\
\text { combination therapy } \\
\text { etanercept with } \\
\text { fumarates }\end{array}$ & p value \\
\hline Week 12 & $5.5 \pm 6.8$ & $7.1 \pm 6.9$ & 0.53 \\
Week 24 & $5.4 \pm 7.9$ & $7.1 \pm 6.4$ & 0.56 \\
Week 48 & $9.4 \pm 8.6$ & $7.3 \pm 6.2$ & 0.51 \\
\hline
\end{tabular}

Results are expressed as means \pm SD. $p$ values assessed by the unpaired t test.

Combination Therapy of Etanercept and Fumarates
Table 4. Treatment satisfaction measured by visual analogue scale (VAS) from 0 to 10

\begin{tabular}{llll}
\hline & $\begin{array}{l}\text { VAS monotherapy } \\
\text { etanercept }\end{array}$ & $\begin{array}{l}\text { VAS combination } \\
\text { therapy etanercept } \\
\text { and fumarates }\end{array}$ & p value \\
\hline Week 12 & $8.0 \pm 1.47$ & $8.1 \pm 1.55$ & 0.92 \\
Week 24 & $8.1 \pm 1.45$ & $8.1 \pm 1.43$ & 0.95 \\
Week 48 & $8.9 \pm 1.17$ & $8.2 \pm 1.70$ & 0.30 \\
\hline
\end{tabular}

Results are expressed as means \pm SD. p values assessed by the unpaired $t$ test. 
Table 5. Adverse events

Monotherapy etanercept Patients,

n

Minor adverse events

Gastrointestinal complaints

Flushing

Elevation of liver enzymes

Influenza-like symptoms

Headache

Fatigue

Pruritus

Injection site reactions

Operation

Other

Major adverse events

Serious adverse event

Severe adverse event

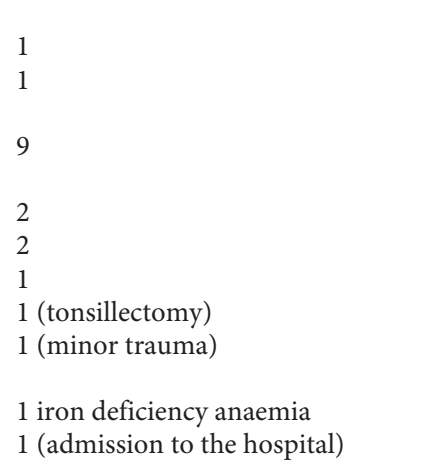

1

1

1

1

1 Combination therapy etanercept with fumarates

Patients,

$\begin{array}{lr}38 & 11 \\ 4 & 4 \\ 1 & 1 \\ 14 & 10 \\ 1 & 1 \\ 1 & 1 \\ 2 & 2 \\ 1 & 1 \\ 2 \text { (meniscus surgery) } & 1 \\ & 2 \\ 2 \text { (admission to the hospital) } & 1\end{array}$

using a linear mixed model analysis yielded no significant differences in efficacy between the two treatment groups.

Using the PGA as a secondary outcome measure, the combination therapy with fumarates resulted in a trend towards better efficacy during the first 24 weeks compared to etanercept monotherapy. The $94 \%$ of patients with a PGA of clear/almost clear in the combination group were remarkably high, and the difference with the monotherapy group approached statistical significance. Furthermore, the DLQI and visual analogue scale score did not differ between the two groups, suggesting that concomitant use of fumarates (and related side effects) did not negatively affect the quality of life and treatment satisfaction in our patients.

The efficacy rates observed in our study [23] are comparable with those of Gottlieb and his group $[9,12]$ whereby 239 patients were randomized to etanercept monotherapy or etanercept with methotrexate (MTX). After 24 weeks, the PASI-75 was significantly higher in the etanercept with MTX group than in the etanercept monotherapy group (77.3 vs. $60.3 \%$; $p<0.0001)$.

In daily practice MTX is more frequently combined with biologics than fumarates, because it is assumed that (low-dose) MTX increases the clinical efficacy of biologics by reducing the development of antidrug antibodies $[23,24]$. Anti-etanercept antibodies have only sporadically been observed in clinical studies, indicating that loss of clinical efficacy for etanercept is probably caused by other, yet unidentified factors [25]. We argued that for improvement of the clinical efficacy of etancercept, inhibition of antidrug antibodies was less important, and that combination with oral fumarates could have an additive clinical effect.
Wilsmann-Theis et al. [26] performed a retrospective study on combination therapies in which they concluded that fumarates could be safely combined with biologics in an off-label real-life setting. Although a similar fumarate dose of 4 times $215 \mathrm{mg}$ a day as in our study was used, their study comprised only 4 patients with fumarates in combination with etanercept. In 2 cases, fumarates were added to etanercept treatment, while the other 2 patients had started on fumarates and were subsequently treated additionally with etanercept. Only 2 of the 4 cases showed a good clinical response to the combination treatment after 6 months and 2 years [26]. Fumarates have also been used in combination with other systemic agents such as cyclosporin, acitretin, hydroxyurea and MTX [27]. However, no prospective randomized clinical trials were performed to evaluate the efficacy and safety of these combinations [28].

This is the first prospective randomized trial to show that combination therapy with fumarates appears to be relatively safe and to have an acceptable tolerability up to 48 weeks. Since higher doses of fumarates are known to be associated with an increased incidence of side effects, an adjusted dose of up to $215 \mathrm{mg} 4$ times a day was used instead of the commonly used maximum dose of 6 tablets a day. We believe that therefore no patients had to discontinue treatment with fumarates because of side effects. A common and potential serious side effect of fumarates, leucopenia and/or lymphopenia, was not observed in any of our patients during the 1-year course of the study either. This is particularly of interest because of the recently reported cases of progressive multifocal leucencephalopathy in long-term fumaric acid users. It has to be noted that most of the reported progressive multifocal 
leucencephalopathy cases were lymphopenic for a prolonged period.

It is remarkable that the occurrence of gastrointestinal side effects in the combination therapy group did not lead to a significantly altered quality of life, as expressed by the DLQI, or less treatment satisfaction. When a higher dose had been used, we potentially could have achieved a higher efficacy and statistically significant differences between the two groups. However, this could also have resulted in more drop-outs because of fumarate-related side effects.

This study was performed in a real-life clinical setting and was therefore confronted with some practical clinical limitations from daily practice. First of all, we had issues with patient compliance. Three patients ( 1 in the monotherapy and 2 in the combination therapy group) decided, for personal reasons and despite a clear/almost clear clinical response at week 24, to withdraw consent and to discontinue the study. Secondly, the combination therapy group contained significantly more patients who had previously used and failed one or more biologics, namely $56 \%$ against $20 \%$ in the monotherapy group. Several studies have shown that patients with prior use of biologics have a shorter drug survival in comparison with biologic-naïve patients $[7,29,30]$. However, in daily clinical practice nonnaïve patients also require treatment. Furthermore, patients were not blinded to treatment as we did not use placebo fumarate tablets in the etanercept monotherapy arm. However, the 'blinding effects' of placebo tablets would have been minimal due to the high frequency of gastrointestinal complaints typically associated with fumarates. Finally, in the etanercept monotherapy group, 5 patients were switched to the combination therapy because of inefficacy. However, only 1 of these 5 patients showed a clear improvement after the addition of fumarates to etanercept, the other 4 had persistent brittle psoriasis and did not achieve a PASI-75 response and had to be switched to other biologics after week 48 . These 4 patients were notorious therapy-resistant patients who had failed several other antipsoriatic therapies including biologics.

In conclusion, in this study, using the PGA, the combination therapy showed a trend towards a faster rate of improvement in the first 24 weeks. The difference in PASI score between the two groups was not statistically significant. Addition of fumarates to etanercept for 48 weeks appeared safe with an acceptable tolerability.

\section{Statement of Ethics}

This study was approved by the Institutional Review Board of the Erasmus University Medical Center Rotterdam (MEC-2011500) and the national medical authority (Central Committee on Research Involving Human Subjects). All patients provided written informed consent. The study was conducted according to the guidelines of Good Clinical Practice.

\section{Disclosure Statement}

Investigator-initiated project grant from Pfizer. E. Prens has acted as a consultant for AbbVie, Amgen, Astra-Zeneca, Baxter, Eli Lilly, Galderma, Janssen-Cilag, Novartis and Pfizer and has received investigator-initiated research grants (paid to Erasmus MC) from Pfizer, Janssen-Cilag and AbbVie. M.B.A. van Doorn has acted as a consultant for Abbott, Janssen, LEO Pharma, MSD and Pfizer, and has been an investigator for Eli Lilly, Idera Pharmaceuticals, Cutanea and Novartis. T. van Gelder has been on the speakers' bureau or worked as consultant for Sandoz, Novartis, Teva, Chiesi, Astellas and Roche.

\section{References}

1 Raychaudhuri SP, Farber EM: The prevalence of psoriasis in the world. J Eur Acad Dermatol Venereol 2001;15:16-17.

-2 Rapp SR, Feldman SR, Exum ML, Fleischer $\mathrm{AB}$ Jr, Reboussin DM: Psoriasis causes as much disability as other major medical diseases. J Am Acad Dermatol 1999;41:401407.

3 Stern RS, Nijsten T, Feldman SR, Margolis DJ, Rolstad T: Psoriasis is common, carries a substantial burden even when not extensive, and is associated with widespread treatment dissatisfaction. J Investig Dermatol Symp Proc 2004;9:136-139.

4 Mrowietz U, de Jong EM, Kragballe K, Langley R, Nast A, Puig L, Reich K, Schmitt J, War-

Combination Therapy of Etanercept and Fumarates ren RB: A consensus report on appropriate treatment optimization and transitioning in the management of moderate-to-severe plaque psoriasis. J Eur Acad Dermatol Venereol 2014;28:438-453.

- 5 Zandvliet ML, van Bezooijen JS, Bos MA, Prens EP, van Doorn M, Bijen I, Schreurs MW, van der Velden VH, Koch BC, van Gelder T: Monitoring antigen-specific biologics: current knowledge and future prospects. Ther Drug Monit 2013;35:588-594.

-6 Gniadecki R, Kragballe K, Dam TN, Skov L: Comparison of drug survival rates for adalimumab, etanercept and infliximab in patients with psoriasis vulgaris. Br J Dermatol 2011; 164:1091-1096.
7 Van den Reek JM, van Lumig PP, Driessen RJ, van de Kerkhof PC, Seyger MM, Kievit W, de Jong EM: Determinants of drug survival for etanercept in a long-term daily practice cohort of patients with psoriasis. Br J Dermatol 2014;170:415-424.

-8 Gniadecki R, Bang B, Bryld LE, Iversen L, Lasthein S, Skov L: Comparison of long-term drug survival and safety of biologic agents in patients with psoriasis vulgaris. Br J Dermatol 2015;172:244-252.

$\checkmark 9$ Leonardi CL, Powers JL, Matheson RT, Goffe BS, Zitnik R, Wang A, Gottlieb AB; Etanercept Psoriasis Study Group: Etanercept as monotherapy in patients with psoriasis. $\mathrm{N}$ Engl J Med 2003;349:2014-2022. 
10 Cassano N, Loconsole F, Galluccio A, Miracapillo A, Pezza M, Vena GA: Once-weekly administration of high-dosage etanercept in patients with plaque psoriasis: results of a pilot experience (power study). Int J Immunopathol Pharmacol 2006;19:225-229.

-11 Papp KA, Tyring S, Lahfa M, Prinz J, Griffiths CE, Nakanishi AM, Zitnik R, van de Kerkhof PC, Melvin L; Etanercept Psoriasis Study Group: A global phase III randomized controlled trial of etanercept in psoriasis: safety, efficacy, and effect of dose reduction. Br J Dermatol 2005;152:1304-1312.

-12 Tyring S, Gottlieb A, Papp K, Gordon K, Leonardi C, Wang A, Lalla D, Woolley M, Jahreis A, Zitnik R, Cella D, Krishnan R: Etanercept and clinical outcomes, fatigue, and depression in psoriasis: double-blind placebocontrolled randomised phase III trial. Lancet 2006;367:29-35.

13 Nast A, Boehncke WH, Mrowietz U, Ockenfels HM, Philipp S, Reich K, Rosenbach T, Sammain A, Schlaeger M, Sebastian M, Sterry W, Streit V, Augustin M, Erdmann R, Klaus J, Koza J, Muller S, Orzechowski HD, Rosumeck S, Schmid-Ott G, Weberschock T, Rzany B; Deutsche Dermatologische Gesellschaft, Berufsverband Deutscher Dermatologen: S3 - guidelines on the treatment of psoriasis vulgaris (English version). Update. J Dtsch Dermatol Ges 2012;10(suppl 2):S1-S95.

$>14$ Foley PA, Quirk C, Sullivan JR, Dolianitis C, Hack SP, Thirunavukkarasu K, Cooper AJ: Combining etanercept with traditional agents in the treatment of psoriasis: a review of the clinical evidence. J Eur Acad Dermatol Venereol 2010;24:1135-1143.

15 Heffernan MP: Combining traditional systemic and biologic therapies for psoriasis. Semin Cutan Med Surg 2010;29:67-69.
16 Wilsmann-Theis D, Frambach Y, Philipp S, Weyergraf AJ, Jacobi A, Mossner R, Gerdes S: Systemic antipsoriatic combination therapy with fumaric acid esters for plaque-type psoriasis: report on 17 cases. Dermatology 2015; 230:119-127.

17 Calzavara-Pinton PG, Sala R, Arisi M, Rossi MT, Venturini M, Ortel B: Synergism between narrowband ultraviolet $\mathrm{B}$ phototherapy and etanercept for the treatment of plaquetype psoriasis. Br J Dermatol 2013;169:130136.

18 Warren RB, Brown BC, Lavery D, Ashcroft DM, Griffiths CE: Biologic therapies for psoriasis: practical experience in a UK tertiary referral centre. Br J Dermatol 2009;160:162169.

19 Reich K, Thaci D, Mrowietz U, Kamps A, Neureither M, Luger T: Efficacy and safety of fumaric acid esters in the long-term treatment of psoriasis - a retrospective study (future). J Dtsch Dermatol Ges 2009;7:603-611.

20 Hoefnagel JJ, Thio HB, Willemze R, Bouwes Bavinck JN: Long-term safety aspects of systemic therapy with fumaric acid esters in severe psoriasis. Br J Dermatol 2003;149:363369.

21 Wain EM, Darling MI, Pleass RD, Barker JN, Smith CH: Treatment of severe, recalcitrant, chronic plaque psoriasis with fumaric acid esters: a prospective study. Br J Dermatol 2010; 162:427-434.

22 Fallah Arani S, Neumann H, Hop WC, Thio HB: Fumarates vs methotrexate in moderate to severe chronic plaque psoriasis: a multicentre prospective randomized controlled clinical trial. Br J Dermatol 2011;164:855-861.

23 Van Bezooijen JS, Prens EP, Pradeepti MS, Atiqi R, Schreurs MW, Koch BC, van Gelder $\mathrm{T}$, van Doorn MB: Combining biologics with methotrexate in psoriasis: a systematic review. Br J Dermatol 2015;172:1676-1680.
24 Armstrong AW, Bagel J, Van Voorhees AS, Robertson AD, Yamauchi PS: Combining biologic therapies with other systemic treatments in psoriasis: evidence-based, best-practice recommendations from the medical board of the national psoriasis foundation. JAMA Dermatol 2015;151:432-438.

25 Krieckaert CL, Jamnitski A, Nurmohamed MT, Kostense PJ, Boers M, Wolbink G: Comparison of long-term clinical outcome with etanercept treatment and adalimumab treatment of rheumatoid arthritis with respect to immunogenicity. Arthritis Rheum 2012;64: 3850-3855.

26 Wilsmann-Theis D, Frambach Y, Philipp S, Weyergraf AJ, Jacobi A, Mossner R, Gerdes S: Systemic antipsoriatic combination therapy with fumaric acid esters for plaque-type psoriasis: report on 17 cases. Dermatology 2015; 230:119-127.

27 Balasubramaniam P, Stevenson O, BerthJones J: Fumaric acid esters in severe psoriasis, including experience of use in combination with other systemic modalities. Br J Dermatol 2004;150:741-746.

28 Busard C, Zweegers J, Limpens J, Langendam M, Spuls PI: Combined use of systemic agents for psoriasis: a systematic review. JAMA Dermatol 2014;150:1213-1220.

29 Lopez-Ferrer A, Vilarrasa E, Gich IJ, Puig L: Adalimumab for the treatment of psoriasis in real life: a retrospective cohort of 119 patients at a single Spanish centre. Br J Dermatol 2013; 169:1141-1147.

30 Piaserico S, Cazzaniga S, Chimenti S, Giannetti A, Maccarone M, Picardo M, Peserico A, Naldi L; Psocare Study Group: Efficacy of switching between tumor necrosis factor-alfa inhibitors in psoriasis: results from the Italian Psocare registry. J Am Acad Dermatol 2014; 70:257-262. 